\title{
Risk Factors for Success, Complications, and Death after Endoscopic Sphincterotomy for Bile Duct Stones: A 17-Year Experience with 2,137 Cases
}

\author{
Júlio Carlos Pereira Lima ${ }^{a}$ Ivan David Arciniegas Sanmartin ${ }^{a}$ \\ Bruna Latrônico Palma ${ }^{a}$ Carlos Eduardo Oliveira dos Santos ${ }^{b}$ \\ aDepartment of Gastroenterology, Hepatology and Endoscopy, Santa Casa Hospital, Federal University of \\ Health Sciences of Porto Alegre (UFCSPA), Porto Alegre, Brazil; 'bepartment of Gastroenterology and Endoscopy, \\ Santa Casa Hospital, Bagé, Brazil
}

\author{
Keywords \\ Endoscopic retrograde cholangiopancreatography . \\ Endoscopic sphincterotomy · Bile duct stones . \\ Complication - Post-endoscopic retrograde \\ cholangiopancreatography pancreatitis
}

\begin{abstract}
Background: Risk factors for post-endoscopic retrograde cholangiopancreatography (ERCP) complications are wellstudied. However, risk factors for complications and success after endoscopic sphincterotomy (EST) for duct stones are poorly determined. This study aimed to verify risk factors for mortality, complications, and success after EST. Methods: A multivariate analysis was carried out in a dataset of ERCPs performed during 17 years. Results: A total of5,226 ERCPs were performed, of which 2,137 were in patients with bile duct stones $(1,458$ women and 679 men; mean age $=57$ years) who underwent EST with attempted stone removal. There were 171 (8\%) complications, with pancreatitis in 87 $(4.1 \%)$, bleeding in $48(2.2 \%)$, other complications in 36 $(1.8 \%)$, and mortality of $0.6 \%$. Successful stone(s) removal was obtained in 2,028 cases (94.9\%). On multivariate analysis, mortality was associated with age $>60$ years ( 1 vs. $0.2 \%$ ),
\end{abstract}

cholangitis (4.3 vs. $0.3 \%)$, and EST-related complications (5.8 vs. $0.2 \%)$. Complications were associated with unsuccessful stone removal (13.4 vs. $7.5 \%$ ) and difficult cannulation (13.9 vs. 5.4\%). An unsuccessful EST was independently related to difficult cannulation (86.2 vs. $98.7 \%$ ), precutting (79.4 vs. $96.4 \%$ ), and complications ( 86.5 vs. $95.6 \%)$. Conclusions: Risk factors for complications after EST for stones are delayed bile duct cannulation and failed stone retrieval. Mortality is higher in older patients, those who presented with an EST-related complication, or those who presented initially with cholangitis. Difficult cannulation, EST-related complications, and precutting were associated with an unsuccessful procedure. In this series, outpatient EST with attempted stone retrieval was found to be as safe as performing the procedure in hospitalized patients.

(c) 2020 S. Karger AG, Basel

\section{Introduction}

Endoscopic retrograde cholangiopancreatography (ERCP) is the endoscopic procedure with the highest complication rate, ranging from 5 to $40 \%$ in different series $[1,2]$. The diagnostic and therapeutic utility of ERCP

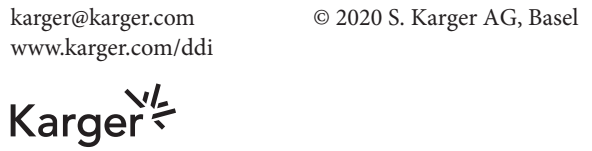

Dr. Ivan David Arciniegas Sanmartin

Department of Gastroenterology, Hepatology and Endoscopy Santa Casa Porto Alegre, Rua Ferreira Viana 187

Porto Alegre 90670100 (Brazil)

davidarciniegas23@gmail.com 
has been well demonstrated for a variety of conditions, including the diagnosis and management of biliary or pancreatic postoperative complications, biliary and pancreatic neoplasias, and the management of bile duct stones, ERCP's index therapeutic adventure $[2,3]$.

The role of biliary endoscopy has evolved simultaneously with other methods, mostly magnetic resonance cholangiopancreatography, which had a major impact in reducing the number of diagnostic ERCPs and laparoscopic cholecystectomy, which exponentially increased the demand for the endoscopic treatment of choledocholithiasis.

Many single-center [4-6] and multicenter studies [711] analyzed risk factors for post-ERCP complications, but almost all of them included very heterogeneous patient populations, such as diagnostic ERCPs in about a quarter of the cases $[4-6,8,9,12-14]$ or precut papillotomy without biliary cannulation in $10-20 \%$ of the patients $[6,8,9]$, and some American series included 25$40 \%$ of patients with suspected sphincter of Oddi dysfunction (SOD) $[4,10,11,15]$, that is, studies that analyzed risk factors for post-ERCP complications included patients with different conditions, different therapeutic approaches, and even patients who did not undergo sphincterotomy or any therapeutic intervention.

This way, the aim of this study was to identify risk factors for complications, success, and death related to endoscopic sphincterotomy (EST) for bile duct stones, the chief indication of therapeutic ERCP, by analyzing a very large single-center collected dataset.

\section{Patients and Methods}

\section{Data Collection}

Consecutively performed ERCPs with EST, defined as any endoscopic procedure carried out with an intention to cannulate the bile duct in patients with known or suspected bile duct stones, were included in this study. ERCP procedures executed (with or without a fellow) by the first author were recorded using standardized paper proformas. These were manually checked and entered into a database, regarding all biliary endoscopies in our institution since 1997-2013.

Data were collected and inserted after completion of follow-up in each case. In this time frame, we have attempted to perform 5,226 ERCPs, with 2,137 (1,458 women/679 men) of these being for confirmed bile duct stones in followed-up naive papilla patients. Patients with intra- and extrahepatic stones were analyzed as one sole group. The majority of the procedures were performed on an outpatient basis $(n=1,517)$. At the end of an observation period of 3-6 h, the patient had a clinical evaluation, and blood tests or radiological studies were done, if necessary. If the patient was asymptomatic, he/she was discharged with an information leaflet encouraging to report adverse events and containing even

Risk Factors for Success, Complications, Death after Endoscopic Sphincterotomy the physician's cell phone number. Other patients included were those who came from inpatient wards, the emergency ward, or other hospitals $(n=620)$ (Table 1 .

A check involving contact with the patients or their caregivers was made 48-72 $\mathrm{h}$ after ERCP in order to verify the development of complications or unscheduled return to hospital. In case of complications, the patient's physicians were also contacted, and the follow-up was checked until discharge or death. All patients or her/ his responsible family member signed informed consent prior to the procedure. This study was approved by our institutional ethics committee and numbered as 1833/12.

\section{Definitions}

Endoscopic cannulation procedure was initially attempted with a sphincterotome (various types and brands along these 17 years); in case of non-cannulation, a guide-wire was used in order to promote deep biliary cannulation. Precut papillotomy was performed with a needle-knife papillotome (NKP), and the cut was begun at the papillary roof always away from the papillary orifice and extended upward or downward in short increments using blended current. Sphincterotomy was then completed in the conventional manner after successful cannulation. After complete EST with blended current, stones were retrieved with an extraction balloon or basket, at the endoscopist's discretion. Mechanical lithotripsy was also performed in 291 cases (13.6\%) with different mechanical lithotriptor models, when judged necessary. Biliary balloon dilation was not performed in this series. When stone retrieval failed, a $10 \mathrm{~F}$ plastic stent was inserted. A pancreatic stent was never placed during these procedures, and post-ERCP pancreatitis (PEP) prophylaxis with drugs was never performed. Cannulation difficulty was determined by the time frame until deep biliary intubation; difficult cannulation was defined as more than $8 \mathrm{~min}$ until deep biliary cannulation; precut procedure was performed only after $12-15 \mathrm{~min}$ of failed cannulation attempts. Bile duct dilation was considered when the duct diameter was $>1 \mathrm{~cm}$ at an imaging exam. Patients with stones and non-naive papilla, with failed ERCP attempts at other institutions, lost to follow-up, or with Billroth II gastrectomy were excluded from the analysis.

\section{Definition of Complications}

ERCP-related complications were defined and graded based on severity according to the consensus criteria developed by Cotton et al. [16]. Pancreatitis (PEP) was considered as new onset abdominal pain associated with an amylase and lipase concentration at least 3 times above the normal range, $24 \mathrm{~h}$ or more after the procedure. Cholangitis was defined as a fever of $38^{\circ} \mathrm{C}$ occurring for more than $24 \mathrm{~h}$ in the absence of an alternative explanation. Hemorrhage was defined as clinically overt bleeding. Perforation was diagnosed based on clinical, radiological, and tomographic findings. Miscellaneous events were attributed to ERCP (e.g., cholecystitis) if the onset of symptoms began within $72 \mathrm{~h}$ of the endoscopic procedure.

In case of patients with active pancreatitis or cholangitis at the time of ERCP, subsequent deterioration or death was not considered as a complication (except for perforation or bleeding).

Outpatients were usually discharged 3-6 h after the procedure if they were judged fit by the medical staff. If not, a direct hospital admission was provided. Readmission was defined when the patient needed to be readmitted into the hospital due to the development of ERCP-related complications after an apparently safe discharge. 
Table 1. Patient characteristics

\begin{tabular}{lc}
\hline Characteristic & Patients \\
\hline Mean age of patient, years & $57(0.8-104)$ \\
Female patients, $n / N(\%)$ & $1,458 / 2,137(68.2)$ \\
ERCP total & 5,226 \\
Ductal stones, $n(\%)$ & $2,137(40.8)$ \\
Sphincter of Oddi dysfunction, $n(\%)$ & $16(0.3)$ \\
Chronic pancreatitis, $n(\%)$ & $82(1.6)$ \\
Surgical leaks/stricture, $n(\%)$ & $124(2.4)$ \\
Neoplasia, $n$ (\%) & $781(14.9)$ \\
Non-naive papilla, previous gastric surgery, previous ERCP & \\
$\quad$ attempts at other institutions, lost to follow-up, $n(\%)$ & $1,497(28.6)$ \\
Spontaneous stone passage or normal findings & $538(10.2)$ \\
Other, $n(\%)$ & $51(0.97)$ \\
\hline
\end{tabular}

ERCP, endoscopic retrograde cholangiopancreatography.

Table 2. Complications and mortality after EST for duct stones

\begin{tabular}{lcl}
\hline Complication & $N$ & $\%$ \\
\hline Acute pancreatitis & 87 & 4.1 \\
Bleeding & 48 & 2.2 \\
Cholangitis & 21 & 1 \\
Perforation & 7 & 0.3 \\
Other & 8 & 0.4 \\
\hline Total & 171 & 8 \\
\hline 30-day mortality (after the procedure), $n / N$ & $13 / 2,137$ & 0.6 \\
\hline
\end{tabular}

EST, endoscopic sphincterotomy.

\section{Statistical Analysis}

Data were presented as mean, or frequency and percentage. We performed associations between variables with the $\chi^{2}$ tests. For comparing continuous variables, a Student's $t$ test or an unequal variance $t$ test was used.

We performed additional exploratory subgroup analyses using multinomial logistic regression analyses to investigate if demographic components and interventional procedures were associated with complications, success, difficult cannulation, and mortality. The multivariate model was built in these steps: demographic components and interventional procedures associated with the outcomes $(p<0.05)$ in univariate analysis were included in a multivariate model and considered statistically significant if the overall $p$ value was $<0.05$. Analyses were performed using STATA Intercooled 13.1 (STATA Corporation, College Station, TX, USA).

\section{Results}

In a 17-year period, 5,226 ERCPs were performed by one sole endoscopist in our unit. Of these, 2,137 (1,458 F, $679 \mathrm{M})$ were in patients with bile duct stones and naive papilla (Table 1). The mean age was 57 years $(0.8-104$ years). At clinical presentation, $6.5 \%$ (138) had cholangitis and $9.5 \%(204)$ had pancreatitis, and peri-papillary diverticula were presented in 311 cases (14.6\%).

Precutting was performed in 194 cases (9.4\%). In an intention-to-treat analysis, bile duct clearance was achieved at the first or second attempt in 2,028 patients (94.9\%). In total, 171 (8\%) patients who underwent EST for choledochal stones developed at least 1 complication, and 13 patients died within 30 days of the procedure $(0.6 \%)$ (Table 2).

\section{Risk Factors for Complications}

On multivariate analysis, only difficult bile duct cannulation and an unsuccessful procedure were associated with complications as a whole. Non-dilated bile duct, small papilla, and duodenal diverticula were not associated in univariate analysis. Precut and cholangitis at clinical presentation were associated in univariate analysis, but not on multivariate analysis. These findings are depicted in Table 3. In all, 91 of 654 (13.9\%) cases with difficult cannulation presented with a procedure-related complication in comparison to 80 of $1,483(5.4 \%)$ without reported difficult bile duct cannulation $(p<0.0001)$.

An ERCP-related complication was associated with an unsuccessful bile duct stone clearance. Successful stone retrieval occurred in 148/171 (86.5\%) patients who experienced a complication, in comparison to $95.6 \%$ $(1880 / 1996)$ who did not experience a complication $(p<$ 0.001 ). Seen other way, unsuccessful stone retrieval had a $13.4 \%$ complication rate in comparison to a successful procedure $(7.5 \%)$. Difficult bile duct cannulation was also associated specifically with PEP ( $p<0.003,8.1$ vs. $2.3 \%)$, but to perforation only in univariate analysis ( 0.1 vs. 
Table 3. Univariate and multivariate analysis of factors associated with complications after attempted EST with stone retrieval

\begin{tabular}{|c|c|c|c|c|c|c|}
\hline \multirow[t]{2}{*}{ Complication } & \multicolumn{2}{|l|}{ Present } & \multicolumn{2}{|l|}{ Absent } & \multirow[t]{2}{*}{ OR } & \multirow[t]{2}{*}{$p$ value } \\
\hline & $n / N$ & $\%$ & $n / N$ & $\%$ & & \\
\hline Difficult cannulation $^{\mathrm{a}}$ & $91 / 654$ & 13.9 & $80 / 1,483$ & 5.4 & $2.83(2.06-3.88)$ & 0.0001 \\
\hline Small papilla & $8 / 72$ & 11.1 & $163 / 2,065$ & 7.8 & $1.28(0.91-1.65)$ & 0.08 \\
\hline Unsuccessful ERCPa & $23 / 171$ & 13.4 & $148 / 1,966$ & 7.5 & $1.68(1.32-2.14)$ & 0.001 \\
\hline Cholangitis & $19 / 138$ & 13.7 & $152 / 1,999$ & 7.6 & $1.62(1.11-2.13)$ & 0.02 \\
\hline Precut & $31 / 194$ & 15.9 & $140 / 1,943$ & 7.2 & $1.87(1.37-2.38)$ & 0.0001 \\
\hline
\end{tabular}

EST, endoscopic sphincterotomy; ERCP, endoscopic retrograde cholangiopancreatography; OR, odds ratio. ${ }^{\text {a }}$ Positive association in multivariate analysis.

Table 4. Univariate and multivariate analysis for mortality after attempted EST with stone retrieval

\begin{tabular}{|c|c|c|c|c|c|c|}
\hline \multirow[t]{2}{*}{ Death } & \multicolumn{2}{|l|}{ Present } & \multicolumn{2}{|l|}{ Absent } & \multirow[t]{2}{*}{ OR } & \multirow[t]{2}{*}{$p$ value } \\
\hline & $n / N$ & $\%$ & $n / N$ & $\%$ & & \\
\hline Cholangitis $^{\mathrm{a}}$ & $6 / 138$ & 4.3 & $7 / 1,999$ & 0.3 & $15.09(4.8-47.4)$ & 0.0001 \\
\hline Pancreatitis (PEP) & $2 / 204$ & 1 & $11 / 1,933$ & 0.5 & $1.90(0.41-8.75)$ & 0.40 \\
\hline Precutting & $2 / 194$ & 1 & $11 / 1,943$ & 0.5 & $2.01(0.43-9.25)$ & 0.35 \\
\hline Age over 60 years $^{a}$ & $11 / 1,108$ & 1 & $2 / 1,029$ & 0.2 & $6.18(2.25-10.15)$ & 0.019 \\
\hline Small papilla & $1 / 72$ & 1.4 & $12 / 2,065$ & 0.5 & $2.63(0.33-20.65)$ & 0.33 \\
\hline Duodenal diverticulum & $2 / 311$ & 0.6 & $11 / 1,826$ & 0.5 & $1.17(0.25-5.39)$ & 0.83 \\
\hline Biliary dilation & $8 / 1,196$ & 0.7 & $5 / 941$ & 0.5 & $1.57(0.47-5.25)$ & 0.45 \\
\hline Jaundice & $5 / 229$ & 1.5 & $8 / 1,808$ & 0.4 & $3.97(1.25-12.58)$ & 0.01 \\
\hline Difficult cannulation & $5 / 654$ & 0.7 & $8 / 1,483$ & 0.5 & $1.13(0.34-3.78)$ & 0.83 \\
\hline EST complications ${ }^{\mathrm{a}}$ & $10 / 171$ & 5.8 & $3 / 1,966$ & 0.2 & $60.99(13.25-280.7)$ & 0.001 \\
\hline
\end{tabular}

EST, endoscopic sphincterotomy; PEP, post-ERCP pancreatitis. ${ }^{\text {a }}$ Positive association in multivariate analysis.

$0.9 \%)$. Cholangitis at clinical presentation was specifically associated with post-EST bleeding in a statistically significant fashion (13/138 [9.4\%] vs. 35/1,999 [1.75\%]), but not with other complications. The use of mechanical lithotripsy was clearly not associated with complications (26 of 291 [8.9\%] vs. 145 of 1,846 [7.8\%]).

Complications occurred in 113 of 1,517 (7.4\%) outpatient ESTs in comparison to 58/620 inpatient ESTs (9.3\%) (non-significant). Eleven of 113 cases of outpatient EST have to return to the hospital after an apparently uneventful discharge - all of them with PEP. There were additional cases of post-EST late bleeding or biliary infection that were managed without the need for hospitalization.

\section{Risk Factors for Death}

A fatal outcome was associated on multivariate analysis with post-EST complications $(3 / 1,966$ [0.2] versus 10 [171], 5.8\%, $p=0.0001$, OR $=60.9-13.2-280.7)$, cholan- gitis at clinical presentation ( 7 of 1,999 [0.3\%] vs. 6 of 138 [4.3\%], $p<0.0001, \mathrm{OR}=15.09$ [4.8-47.4]), and age $>60$ years ( 11 of 1,108 [0.99\%] vs. 2 of 1,029 [0.19\%]). Jaundice was associated with death in univariate analysis, but not on multivariate analysis (Table 4).

\section{Factors Associated with Unsuccessful Bile Duct Clearance}

Non-dilated bile duct at imaging procedures before ERCP, performing a precut, not presenting with acute pancreatitis before ERCP, jaundice at clinical presentation, difficult bile duct cannulation, an EST-related complication, and a small papilla were all risk factors for an unsuccessful procedure at univariate analysis. At multivariate analysis, just difficult cannulation, post-EST-related complications, and precutting remained statistically significant (Table 5). Stones' size, location, and amount were not measured in this database, so could not be analyzed. 
Table 5. Univariate and multivariate analysis for successful EST with stone retrieval

\begin{tabular}{|c|c|c|c|c|c|c|}
\hline \multirow{2}{*}{$\begin{array}{l}\text { Successful procedure } \\
(n=2,137)\end{array}$} & \multicolumn{2}{|l|}{ Present } & \multicolumn{2}{|l|}{ Absent } & \multirow[t]{2}{*}{ OR } & \multirow[t]{2}{*}{$p$ value } \\
\hline & $n / N$ & $\%$ & $n / N$ & $\%$ & & \\
\hline Difficult cannulation $^{\mathrm{a}}$ & $564 / 654$ & 86.2 & $1,464 / 1,483$ & 98.7 & $0.081(0.04-0.13)$ & 0.0001 \\
\hline Small papilla & $59 / 72$ & 81.9 & $1,969 / 2,065$ & 95.4 & $0.22(0.11-0.41)$ & 0.0001 \\
\hline Duodenal diverticulum & $291 / 311$ & 93.6 & $1,737 / 1,826$ & 95.1 & $0.74(0.45-1.23)$ & 0.249 \\
\hline Post-EST complication $^{\mathrm{a}}$ & $148 / 171$ & 86.5 & $1,880 / 1,966$ & 95.6 & $0.29(0.18-0.48)$ & 0.0001 \\
\hline Pancreatitis & $200 / 204$ & 98.0 & $1,828 / 1,933$ & 94.6 & $2.87(1.04-7.87)$ & 0.032 \\
\hline Biliary dilation & $1,149 / 1,196$ & 96.1 & $879 / 941$ & 93.4 & $1.72(1.16-2.54)$ & 0.006 \\
\hline Cholangitis & $132 / 138$ & 95.7 & $1,896 / 1,999$ & 94.8 & $1.19(0.51-2.77)$ & 0.678 \\
\hline Jaundice & $302 / 329$ & 92.1 & $1,725 / 1,808$ & 95.4 & $0.56(0.35-0.88)$ & 0.01 \\
\hline Precutting ${ }^{\mathrm{a}}$ & $154 / 194$ & 79.4 & $1,874 / 1,943$ & 96.4 & $0.14(0.09-0.21)$ & 0.0001 \\
\hline
\end{tabular}

EST, endoscopic sphincterotomy; OR, odds ratio. ${ }^{\text {a }}$ Positive association in multivariate analysis.

Table 6. Univariate and multivariate analysis of risk factors for difficult bile duct cannulation

\begin{tabular}{|c|c|c|c|c|c|c|}
\hline \multirow{2}{*}{$\begin{array}{l}\text { Difficult cannulation } \\
(n=2,137)\end{array}$} & \multicolumn{2}{|l|}{ Present } & \multicolumn{2}{|l|}{ Absent } & \multirow[t]{2}{*}{ OR } & \multirow[t]{2}{*}{$p$ value } \\
\hline & $n / N$ & $\%$ & $n / N$ & $\%$ & & \\
\hline Small papilla ${ }^{a}$ & $41 / 72$ & 56.9 & $613 / 2,065$ & 29.7 & $3.13(1.94-5.04)$ & 0.0001 \\
\hline Biliary dilation & $332 / 1,196$ & 27.8 & $322 / 941$ & 34.2 & $0.73(0.61-0.88)$ & 0.001 \\
\hline Duodenal diverticula & $127 / 311$ & 40.8 & $527 / 1,826$ & 28.9 & $1.70(1.32-2.18)$ & 0.0001 \\
\hline Cholangitis & $32 / 138$ & 23.1 & $622 / 1,999$ & 31.1 & $0.66(0.44-1.00)$ & 0.051 \\
\hline Jaundice & $75 / 329$ & 22.8 & $579 / 1,808$ & 32.0 & $0.62(0.47-0.82)$ & 0.001 \\
\hline Pancreatitis ${ }^{\mathrm{a}}$ & $39 / 204$ & 19.1 & $615 / 1,933$ & 31.8 & $0.50(0.35-0.72)$ & 0.0001 \\
\hline
\end{tabular}

OR, odds ratio. ${ }^{\text {a }}$ Positive association in multivariate analysis/small papilla makes cannulation difficult and pancreatitis facilitates cannulation.

Factors Associated with Difficult Cannulation

Patients who presented initially with acute pancreatitis, acute cholangitis, jaundice, and biliary dilation on imaging exams prior to EST had bile ducts easier to cannulate than those who do not. Only pancreatitis at clinical presentation remained statistically significant after multivariate analysis (Table 6).

Patients with duodenal diverticula showed bile ducts more difficult to cannulate $(527 / 1,826$ [28.9\%] vs. $127 / 311$ [40.8\%], OR $1.70[1.32-2.18], p=0.001)$ on univariate analysis (not on multivariate analysis), but this was not associated neither with complications nor with an unsuccessful ERCP. Only a tiny papilla was associated with difficult cannulation on multivariate analysis.

The performance of EST in patients with or without an in situ gallbladder, with or without Kehr's drainage, on an in- or outpatient basis, and gender were not related to complications, difficult cannulation, success, or death.

\section{Discussion}

Numerous studies have been devoted to delineating risk factors for post-ERCP complications, especially for PEP [4$6,17,18]$. Previous reports suggested that patient-related factors such as SOD, female sex, younger age, previous pancreatitis at ERCP, a thin bile duct - a surrogate marker of younger age, SOD, or normal biliary tree - and pancreatic duct injections or guide-wire passes - a surrogate marker of difficult cannulation or long time frame until deep bile duct cannulation - are associated with PEP $[1-4,19,20]$.

This study differs in many aspects from previous studies analyzing post-ERCP complication risk factors. Although the original indication of EST was the removal of duct stones, and bile duct stone extraction remains the main indication for ERCP, most studies dealing with post-ERCP complication risk factors included just a minority of patients with stones. 
Cheng et al. [10] in a multicenter study evaluating PEP risk factors in 1,115 patients reported therapeutic ERCP in just $579(51.9 \%)$ of them and solely 168 (15\%) had choledocholithiasis. Nevertheless, $33.9 \%$ had suspected SOD. Cotton et al. [4] analyzing a 12-year-long experience reported that $25 \%$ and $<20 \%$ of the more than 11,500 procedures were done for suspected SOD and suspected lithiasis, respectively. Furthermore, EST was performed in just $30 \%$ of the 11,500 biliary endoscopies. Other studies dealt with a $20-30 \%$ diagnostic ERCP rate $[5,6,9]$, something that, at least, is unusual in the era of magnetic resonance cholangiopancreatography.

So, these differences in patient population (SOD, nonstone, non-cancer patients) and procedures undertaken (all of our analyzed patients underwent EST with attempted stone removal) show that these above-mentioned data on ERCP-attributable complications may not mirror the real world of most biliary endoscopy units. Indeed, the only study that dealt exclusively with risk factors for complications after EST was the seminal report by Freeman et al. [11], in which $68 \%$ of the sphincterotomies were due to common duct stones.

In this study, analyzing only patients with bile duct stones who underwent EST, only difficulty in cannulation (>8 min until selective bile duct cannulation) was specifically associated with PEP, as well as with complications as a whole. Difficulty in cannulation was also associated with a lower ductal stone clearance rate $(86.2$ vs. 98.7\%). An unsuccessful stone retrieval was also associated with complications as a whole. The other risk factor for post-EST complications was clinical cholangitis at the moment of ERCP, which was specifically associated with post-EST bleeding.

The finding that difficulty in cannulation was independently associated with PEP is supported by many studies $[7,9,11,21]$. Precutting was not associated with complications or PEP in multivariate analysis. In fact, precut supporters argue that the increased risk of complications with this method could be attributed to the previous excessive attempts at bile duct selective cannulation before its employment $[10,22]$ or lower expertise in performing precutting. Cennamo et al. [23] randomized 146 patients with failed cannulation attempts at $5 \mathrm{~min}$ for immediate precut or standard cannulation attempts for further $20 \mathrm{~min}$ followed by precut in case of failure. The complication rate was similar in both groups ( 8 vs. $6 \%$ ); however, a third of the cases of the standard cannulation group needed also a precut. The same authors in a metaanalysis of 6 trials found that in experienced hands, precut neither increases nor decreases the rate of PEP in comparison to persistent standard cannulation attempts [24]. Navaneethan et al. [25] analyzing 7 trials and 1,039 patients found a trend favoring early precut. In these studies, timing until precutting, as well as precut technique, was considerably variable: from 2 to $12 \mathrm{~min}$ of cannulation attempts, and the cut with the NKP begun at the orifice in 4 and at the papillary roof in 3 studies.

In our study, we considered difficulty in cannulation when more than 8 min was needed to achieve deep bile duct catheterization. In fact, precutting was performed only after 12-15 min of attempts. So, these increased number of attempts in a standard manner could be responsible for the increased complication rate observed in patients who underwent precut papillotomy. In other words, patients whose biliary cannulation was delayed by more than $8 \mathrm{~min}$ are at an increased risk of complications, and patients whose cannulation were deferred for more than 12-15 min are at an even greater risk, or, at least, at a greater risk than those whose cannulation was achieved faster. Difficult bile duct cannulation was associated in univariate analysis with perforation, but not on multivariate analysis. This is probably due to the interaction with precutting.

Difficulty in cannulation is not easily quantifiable, and interactions with methods of cannulation, number of attempts, mode of attempts, and number and pressure of pancreatic injections occur. The number of attempts to consider a difficult cannulation varies widely, from 1 attempt [9], 6 attempts [11], 8 attempts [10], to even 20 trials [26]. Other authors quoted this variable as more than $10 \mathrm{~min}$ [7, 22], $12 \mathrm{~min}$, or even $20 \mathrm{~min}$ until cannulation $[24,27]$. Our study did not contemplate issues of repeated injections of contrast into the pancreas, the degree of opacification of the gland, nor the number of guide-wire passes.

There are basically 3 techniques of precutting. Using a NKP, the cut is made starting at the orifice and extended cephalad for a variable distance, the use of the NKP to perform papillary roof incision or fistulotomy (our preferred technique), and a pancreatic trans-sphincteric approach [28]. The performance of fistulotomy appears to be safer [29-31] than the other 2 methods, since it avoids the pancreatic duct, while the trans-sphincteric approach cut the pancreatic sphincter, and the NKP precut starting at the orifice, if not technically well performed, may also reach the pancreatic sphincter. Due to this fact, the 2 latter techniques have similar complication rates [29-31]. Indeed, along all these years, we performed preferentially fistulotomy, but trans-sphincteric cuts were also made, based upon papillary anatomy and procedural indication. 
All of them were quoted as precut. Anatomic factors associated with difficult cannulation were a small papilla and duodenal diverticula (this one only on univariate analysis). Jaundiced patients, those with biliary dilation, and those clinically presenting with acute cholangitis presented with less difficult papillas to cannulate on univariate, but not on multivariate, analysis. Only ongoing pancreatitis was associated with a faster cannulation time on multivariate analysis.

Success in removing duct stones was statistically significantly lower in patients with a small papilla on univariate analysis. These patients (success of 81.9 vs. 95.4\%) have bile ducts that are more difficult to cannulate or have a thinner distal duct, which makes stone retrieval more difficult (papillary balloon dilation was not performed in any case in this series). Those who underwent precut and cases with difficulty in cannulation had a lower success rate too. Precut was independently associated with failed stone removal because in this study, precut was only performed after 12-15 min of fruitless attempts; that is, this association is probably a surrogate marker of an even more delayed bile duct cannulation. Patients who experienced some post-ERCP complication were also at an increased risk for a failed procedure. This means that papillary intubation is the key point for a successful ERCP with attempted stone removal.

Success was higher in patients with dilated ducts and with ongoing acute pancreatitis only on univariate analysis. Although these variables did not reach statistical significance on multivariate analysis, they may be real, since acute pancreatitis was statistically significantly associated with easier bile duct cannulation on multivariate regression and most of these patients have papillary orifices that theoretically are easier to cannulate, since the stones are usually placed distally and press the papillary region, thus enlarging the intraduodenal distal bile duct.

Some patients' characteristics and procedural risk factors were associated with death after the procedure. Older patients and patients with cholangitis at presentation are frailer or have more severe disease and/or comorbidities at clinical presentation. Jaundice, a surrogate marker of more severe disease, was associated with fatal outcome on univariate analysis. Patients who had EST complications ( 0.1 vs. $5.8 \%)$ had also a higher risk of death.

In all, 1,517 of the 2,137 (71\%) ESTs were performed on an outpatient basis. Although the performance of outpatient ERCP has become routine in many units and even considered the standard of care by many biliary endoscopists, it is criticized by many authorities [32]. Because the vast majority of complications are diagnosed within $6 \mathrm{~h}$ of the procedure $[6,33]$, and because of cost containment and shortage of hospital beds in our region, we perform all elective therapeutic ESTs for stone retrieval on an outpatient basis. This approach demonstrated to be very safe in our experience, even for older or jaundiced patients.

In summary, the main risk factors for complications after EST with attempted stone removal are delayed bile duct cannulation and failed stone retrieval. EST-associated mortality is higher in older patients, those who presented with an EST-related complication, or those who presented initially with cholangitis. Difficult cannulation, EST-related complications, and precut were associated with an unsuccessful procedure. In this series, outpatient EST with attempted stone retrieval was found to be as safe as performing the procedure in hospitalized patients.

\section{Statement of Ethics}

This study was approved by the Committees of Ethics in Research (CEP) and the National Commission of Ethics in Research (CONEP) (Protocol number 1833/12). Informed consent was obtained from all patients. The study adheres to the Declaration of Helsinki.

\section{Disclosure Statement}

The authors have no conflicts of interest to declare.

\section{Funding Sources}

This work had no source of funding.

\section{Author Contributions}

Prof. Julio Pereira Lima and Dr. Ivan David Arciniegas Sanmartin contributed in the data analysis, writing the literature review, and drafting, editing, and reviewing the manuscript. Drs. Oliveira and Latrônico contributed in the data analysis and manuscript review. All authors have approved the final version of the manuscript.

\section{References}

1 Vila JJ, Artifon EL, Otoch JP. Post-endoscopic retrograde cholangiopancreatography complications: how can they be avoided? World J Gastrointest Endosc. 2012 Jun 16; $4(6): 241-6$.

2 Chandrasekhara V, Chandrasekhara V, Khashab MA, Muthusamy VR, Acosta RD, Agrawal D, et al. Adverse events associated with ERCP. Gastrointest Endosc. 2017 Jan; 85(1):32-47. 
3 Dumonceau JM, Andriulli A, Elmunzer BJ, Mariani A, Meister T, Deviere J, et al. Prophylaxis of post-ERCP pancreatitis: European Society of Gastrointestinal Endoscopy (ESGE) guideline: updated June 2014. Endoscopy. 2014 Sep;46(9):799-815.

4 Cotton PB, Garrow DA, Gallagher J, Romagnuolo J. Risk factors for complications after ERCP: a multivariate analysis of 11,497 procedures over 12 years. Gastrointest Endosc. 2009 Jul; 70(1):80-8.

5 Salminen P, Laine S, Gullichsen R. Severe and fatal complications after ERCP: analysis of 2555 procedures in a single experienced center. Surg Endosc. 2008 Sep;22(9):1965-70.

6 Rábago L, Guerra I, Moran M, Quintanilla E, Collado D, Chico I, et al. Is outpatient ERCP suitable, feasible, and safe? The experience of a Spanish community hospital. Surg Endosc. 2010 Jul;24(7):1701-6.

7 Wang P, Li ZS, Liu F, Ren X, Lu NH, Fan ZN, et al. Risk factors for ERCP-related complications: a prospective multicenter study. Am J Gastroenterol. 2009 Jan;104(1):31-40.

8 Loperfido S, Angelini G, Benedetti G, Chilovi F, Costan F, De Berardinis F, et al. Major early complications from diagnostic and therapeutic ERCP: a prospective multicenter study. Gastrointest Endosc. 1998 Jul;48(1):1-10.

9 Williams EJ, Taylor S, Fairclough P, Hamlyn A, Logan RF, Martin D, et al. Risk factors for complication following ERCP: results of a large-scale, prospective multicenter study. Endoscopy. 2007 Sep;39(9):793-801.

10 Cheng CL, Sherman S, Watkins JL, Barnett J, Freeman M, Geenen J, et al. Risk factors for post-ERCP pancreatitis: a prospective multicenter study. Am J Gastroenterol. 2006 Jan; 101(1):139-47.

11 Freeman ML, Nelson DB, Sherman S, Haber GB, Herman ME, Dorsher PJ, et al. Complications of endoscopic biliary sphincterotomy. N Engl J Med. 1996 Sep 26;335(13):909-18.

12 Barthet M, Lesavre N, Desjeux A, Gasmi M, Berthezene P, Berdah S, et al. Complications of endoscopic sphincterotomy: results from a single tertiary referral center. Endoscopy. 2002 Dec;34(12):991-7.

13 Christensen M, Matzen P, Schulze S, Rosenberg J. Complications of ERCP: a prospective study. Gastrointest Endosc. 2004 Nov;60(5): 721-31.

14 Christoforidis E, Goulimaris I, Kanellos I, Tsalis K, Demetriades C, Betsis D. Post-ERCP pancreatitis and hyperamylasemia: patientrelated and operative risk factors. Endoscopy. 2002 Apr;34(4):286-92.
15 Andriulli A, Loperfido S, Napolitano G, Niro G, Valvano MR, Spirito F, et al. Incidence rates of post-ERCP complications: a systematic survey of prospective studies. Am J Gastroenterol. 2007 Aug;102(8):1781-8.

16 Cotton PB, Lehman G, Vennes J, Geenen JE, Russell RC, Meyers WC, et al. Endoscopic sphincterotomy complications and their management: an attempt at consensus. Gastrointest Endosc. 1991 May-Jun;37(3):38393.

17 Katsinelos P, Lazaraki G, Chatzimavroudis G, Gkagkalis S, Vasiliadis I, Papaeuthimiou A, et al. Risk factors for therapeutic ERCP-related complications: an analysis of 2,715 cases performed by a single endoscopist. Ann Gastroenterol. 2014;27(1):65-72.

18 Mehta SN, Pavone E, Barkun JS, Bouchard S, Barkun AN. Predictors of post-ERCP complications in patients with suspected choledocholithiasis. Endoscopy. 1998 Jun;30(5):45763.

19 Gong B, Hao L, Bie L, Sun B, Wang M. Does precut technique improve selective bile duct cannulation or increase post-ERCP pancreatitis rate? A meta-analysis of randomized controlled trials. Surg Endosc. 2010 Nov; 24(11):2670-80.

20 Choudhary A, Winn J, Siddique S, Arif M, Arif Z, Hammoud GM, et al. Effect of precut sphincterotomy on post-endoscopic retrograde cholangiopancreatography pancreatitis: a systematic review and meta-analysis. World J Gastroenterol. 2014 Apr 14;20(14): 4093-101.

21 Pereira-Lima JC, Rynkowski CB, Rhoden EL. Endoscopic treatment of choledocholithiasis in the era of laparoscopic cholecystectomy: prospective analysis of 386 patients. Hepatogastroenterology.2001 Sep-Oct;48(41):12714.

22 Bailey AA, Bourke MJ, Kaffes AJ, Byth K, Lee EY, Williams SJ. Needle-knife sphincterotomy: factors predicting its use and the relationship with post-ERCP pancreatitis (with video). Gastrointest Endosc. 2010 Feb;71(2):26671.

23 Cennamo V, Fuccio L, Repici A, Fabbri C, Grilli D, Conio M, et al. Timing of precut procedure does not influence success rate and complications of ERCP procedure: a prospective randomized comparative study. Gastrointest Endosc. 2009 Mar;69(3 Pt 1):473-9.
24 Cennamo V, Fuccio L, Zagari RM, Eusebi LH, Ceroni L, Laterza L, et al. Can early precut implementation reduce endoscopic retrograde cholangiopancreatography-related complication risk? Meta-analysis of randomized controlled trials. Endoscopy. 2010 May;42(5): 381-8.

25 Navaneethan U, Konjeti R, Venkatesh PG, Sanaka MR, Parsi MA. Early precut sphincterotomy and the risk of endoscopic retrograde cholangiopancreatography related complications: an updated meta-analysis. World J Gastrointest Endosc. 2014 May 16; 6(5):200-8.

26 Vandervoort J, Soetikno RM, Tham TC, Wong RC, Ferrari AP Jr, Montes H, et al. Risk factors for complications after performance of ERCP. Gastrointest Endosc. 2002 Nov; 56(5):652-6.

27 Bailey AA, Bourke MJ, Williams SJ, Walsh PR, Murray MA, Lee EY, et al. A prospective randomized trial of cannulation technique in ERCP: effects on technical success and postERCP pancreatitis. Endoscopy. 2008 Apr; 40(4):296-301.

28 Dumonceau JM, Andriulli A, Deviere J, Mariani A, Rigaux J, Baron TH, et al. European Society of Gastrointestinal Endoscopy (ESGE) guideline: prophylaxis of post-ERCP pancreatitis. Endoscopy. 2010 Jun;42(6):50315.

29 Halttunen J, Keränen I, Udd M, Kylänpää L. Pancreatic sphincterotomy versus needle knife precut in difficult biliary cannulation. Surg Endosc. 2009 Apr;23(4):745-9.

30 Katsinelos P, Gkagkalis S, Chatzimavroudis G, Beltsis A, Terzoudis S, Zavos C, et al. Comparison of three types of precut technique to achieve common bile duct cannulation: a retrospective analysis of 274 cases. Dig Dis Sci. 2012 Dec;57(12):3286-92.

31 Testoni PA, Mariani A, Aabakken L, Arvanitakis M, Bories E, Costamagna G, et al. Papillary cannulation and sphincterotomy techniques at ERCP: European Society of Gastrointestinal Endoscopy (ESGE) clinical guideline. Endoscopy. 2016 Jul;48(7):657-83.

32 Pfau PR. Outpatient ERCP: everybody is doing it: does this make it right? Gastrointest Endosc. 2008 Jul;68(1):124-6.

33 Jeurnink SM, Poley JW, Steyerberg EW, Kuipers EJ, Siersema PD. ERCP as an outpatient treatment: a review. Gastrointest Endosc. 2008 Jul;68(1):118-23.
Risk Factors for Success, Complications, Death after Endoscopic Sphincterotomy 